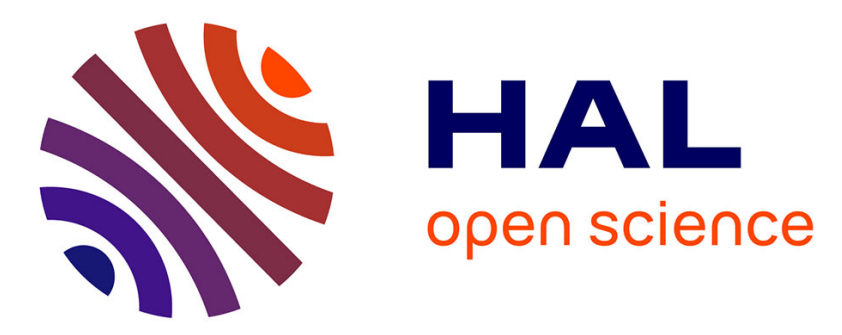

\title{
A novel approach for quantitative measurements of preferential evaporation of fuel by means of two-tracer laser induced fluorescence
}

Michele Bardi, Angela Di Lella, Gilles M Bruneaux

\section{- To cite this version:}

Michele Bardi, Angela Di Lella, Gilles M Bruneaux. A novel approach for quantitative measurements of preferential evaporation of fuel by means of two-tracer laser induced fluorescence. Fuel, 2019, 239, pp.521-533. 10.1016/j.fuel.2018.11.039 . hal-01983551

\section{HAL Id: hal-01983551 \\ https://hal-ifp.archives-ouvertes.fr/hal-01983551}

Submitted on 16 Jan 2019

HAL is a multi-disciplinary open access archive for the deposit and dissemination of scientific research documents, whether they are published or not. The documents may come from teaching and research institutions in France or abroad, or from public or private research centers.
L'archive ouverte pluridisciplinaire HAL, est destinée au dépôt et à la diffusion de documents scientifiques de niveau recherche, publiés ou non, émanant des établissements d'enseignement et de recherche français ou étrangers, des laboratoires publics ou privés. 
1 A novel approach for quantitative measurements of preferential 2 evaporation of fuel by means of two-tracer laser induced 3 fluorescence

\section{Abstract} process.
Michele Bardi, Angela Di Lella, Gilles Bruneaux

IFP Energies Nouvelles (France) - Institut Carnot IFPEN Transports Energie

This paper presents a novel approach for the measurement of vapor fuel concentration at engine relevant conditions for the investigation of preferential evaporation in multicomponent fuel GDI sprays.

The result is achieved by combining in synergy two different tools: i) two-tracer laser induced fluorescence (2T-LIF), a laser diagnostics capable of investigating qualitatively the preferential evaporation by the simultaneous employ of two fluorescent tracers and, ii) a numerical model capable of relating the tracers concentration to the vapor fuel composition.

In order to make this approach reliable for future spray application, this paper presents in details the methodology, including the definition of the surrogate fuel and the tracers. Moreover, results of a fuel evaporation experiment in a simplified environment are presented to validate the numerical model and to assess the uncertainties associated to the technique in spray applications.

The evaporation experiment includes parametric variations of the effect of system pressure (1-5-10 bar), and ethanol concentration ( $0 \%, 20 \%$ and $85 \%$ vol.), exploring problematic relevant to real GDI engines.

The experimental results provided also fundamental understanding of the preferential evaporation

Ethanol is observed to form an azeotrope with lighter compounds segregating the evaporation of the heaviest compounds at the end of the evaporation process.

Finally, the systematic error related to the calculation of vapor phase composition related to the thermodynamic model approximations was assessed for GDI relevant application. The results indicated a very low impact on the final results and discrepancies lower than $5 \%$. 
26 Keywords: GDI, Preferential evaporation, Multicomponent fuel, 2-tracer LIF

\section{Highlights:}

28 1) Novel approach to measure preferential evaporation in GDI sprays

29

2) Fuel vapor composition can be assessed experimentally basing on 2 T-LIF

30

3) A thermodynamic surrogate for commercial gasoline is found

31

4) Preferential evaporation is studied at different ethanol content and evaporation pressures 


\section{Introduction}

33 A highly competitive market and stringent regulations on the pollutant emissions lead engine

34 manufacturers to push to the limit the fundamental research on the in-cylinder related processes [1].

35 During the last two decades, direct fuel injection strategies (DI) have become of common use in compression ignition engines $(\mathrm{Cl})$ and have begun to be a reference also for spark igniting engines (SI)

$37[2,3]$.

$\mathrm{DI}$, in general, enhances the control on fuel mixing and combustion and enables the implementation of new combustion modes, e.g. LTC and multi injections in $\mathrm{Cl}$ engines [4,5] and stratified combustion in SI engines [6]. DI involves several complex physical phenomena including liquid atomization, multiphase flow and multicomponent fuel evaporation $[3,7]$. A real fuel, which is composed by hundreds of compounds of different volatility, can evaporate in a specific fashion normally referred as preferential evaporation. Preferential evaporation takes place when the evaporation process is considered to be slow compared to the mass diffusion of the components within the droplet. This phenomenon causes the lighter compounds to evaporate at different timing than the heavier compounds, and, depending on the mixing process, heterogeneities in the resulting mixture composition might be found. Different studies on GDI engines indicated preferential evaporation as a possible source of heterogeneities in the composition of the resulting air-fuel mixture, by testing cases typical of early or late injection phasing [8-10]. The consequence of preferential evaporation can also be reflected on the combustion process [11], these heterogeneities might result in un-expected / un-wanted effects such as abnormal combustions, or misfires. Few authors carried out experimental studies on GDI sprays evaporation process. In particular, Itani et al. [10] showed experimentally how preferential evaporation leads eventually to heterogeneities in the composition of a vaporized GDI spray under condition typical of stratified combustion strategies.

55 Other authors investigated the effects of preferential evaporation computationally. Zigan et al. [9,12] demonstrated how the evaporation of the droplets is strongly affected by preferential evaporation, and the

57 multicomponent fluid phase change has to be carefully taken into account to have correct predictions of the final fuel vapor distribution [9]. 
The introduction in the market of new oxygenated fuels also represents a new challenge for engine manufacturers. One of the reasons is that the different physical properties of these new fuels [13] yield modifications in the final mixture which are not correctly understood [14]. Storch et al indicated that, physical properties of ethanol blended fuels (E20 and E85) can cause important modifications in the spray formation and in the combustion behavior [15].

Currently, CFD models used for engine development neglects this phenomenon due to the complexity of the physics involved and the lack of quantitative validation data. The experimental investigations available in the literature show only qualitative measurements. To in-cylinder enhance CFD simulations development it is of primary importance to develop quantitative diagnostics that can provide validation data.

The 2T-LIF diagnostic is a technique that has been used in previous studies to investigate preferential evaporation. Krämer et al. employed four different fluorescent tracers (acetone, toluene, p-xylene and 3pentanone) to characterize 3 different volatility compounds of gasoline (low, medium and high) [16]. In their work, they obtained information about the different fuel volatility class in a port fuel engine case by imaging, on different experiments, different couples of tracers. Their results finally indicated heterogeneities in the tracers' distributions and served as a qualitative evidence of heterogeneities in the fuel vapor composition [10]. However, the current need of engine manufacturers in developing predictive CFD models highlights the need of developing a technique to provide validation quantitative data about this important phenomenon, which are currently not available in the literature.

In this work, a novel approach to perform quantitative measurements of preferential evaporation in GDI sprays at real engine conditions is proposed by combining experimental and computational methodologies: an optical diagnostic, 2-Tracer Laser Induced Fluorescence (2T-LIF), and a thermodynamic model for the multi-component fuel evaporation.

The goal of this paper is not to presents experiments on GDI sprays, but it brings important contributions to prove the reliability of the technique for future GDI applications. In particular:

1. It proposes a methodology to obtaine quantitative information of preferential evaporation in GDI sprays. This methodology relies on the combination of $2 \mathrm{~T}$-LIF results and a thermodynamic 
model based on Predictive Soave-Redlich-Kwong state equation. This approach enable to link the tracer concentration measurements to the vapor fuel composition.

2. It provides validation data for the thermodynamic model, by performing evaporation experiments in a simplified environment (a bubbler cell). These experiments, a part from providing validation data, help understanding the effect of boundary conditions on preferential evaporation. In particular, system pressure was varied matching values relevant for GDI engine application (1, 5 and 10 bar). Also, fuel ethanol content effect was tested $(0,20$ and $85 \%$ (vol.)) with the double objective of investigating real world present and future fuels and observing the impact on the fuel evaporation of the addition of a compound with different evaporating properties (ethanol) [17].

3. Finally, the accuracy of the methodology in measuring the vapor fuel composition is assessed. More specifically, the impact of the discrepancies between thermodynamic model results and experimental measurements on the estimation of the fuel vapor composition is presented. This analysis is considered a fair estimation of the accuracy of the technique in GDI applications.

This paper is divided in five sections including the present introduction. One is devoted to the description of the approach, indicating the fuel surrogate composition and the tracers to be used, presenting the details of the thermodynamic models, and the calculations performed to compute the fuel vapor composition. The following section focuses on the description of the experimental setup of the evaporation experiment. The fourth section presents the evaporation experiment results and compares them to the results provided computationally by the thermodynamic model. Also an assessment of the accuracy of the quantitative 2T-LIF is performed on the bases of a deviation analysis. The main conclusions of the paper are then summarized in the final section.

\section{Quantitative interpretation of 2T-LIF results}

\subsection{Global methodology}

$2 T$-LIF is an optical diagnostic capable of investigating the preferential evaporation phenomena in fuel vapor. The technique relies on the simultaneous imaging of the fluorescence signal emitted by two tracers 
of different volatility added to a surrogate, optically transparent fuel. Recent studies demonstrated its applicability to GDI sprays at engine relevant conditions [18]. Similarly to 1-tracer LIF techniques, a laser sheet is used to cause the fluorescence of the tracers. However, in this case, the light emissions are collected by two cameras which, by means of specific spectral filters, provide $2 \mathrm{D}$ information about the fluorescent signal of each tracer separately. As for 1-tracer LIF, by correctly taking into account the photophysics of the tracer, it is possible to establish a relationship between the fluorescent signal and the local mass fraction of the tracer $[19,20]$.

The objective of this paper is to define a methodology to provide quantitative data of fuel preferential evaporation in realistic GDI conditions. To this end, a computational thermodynamic model is coupled to the 2T-LIF to link the tracer concentration to the local fuel composition. In this section, the methodology is described from a

In order to provide a graphic description of the approach proposed, a diagram is presented in Figure 1. As a first step, to carry out $2 \mathrm{~T}$-LIF is necessary to choose carefully the surrogate fuel and the fluorescent tracers:

- The surrogate fuel has to be, on the one hand, optically transparent to assure that only the

Once the fuel and the tracers are correctly selected, 2T-LIF can provide separately each tracer's local mass fraction, and also the tracers' concentration ratio $\left(T_{R}\right)$. The key point of this approach is the employ of a thermodynamic model which is used to calculate the phase change process of a multicomponent fuel taking into account the co-evaporation between compounds of different volatility. 
However, to link the 2T-LIF results to the fuel vapor composition, thanks to the thermodynamic model, some hypotheses about the droplet evaporations are needed, and will be presented later in the paper.

In this paper, the thermodynamic model is applied to fulfill three different tasks:

1. To define the gasoline surrogate composition needed for the optical experiments. The comparison between the distillation curve provided by the model and the one provided by the experiments will also provide a first preliminary validation of the thermodynamic model.

2. For its validation: an experiment is put in place to produce the evaporation of a multicomponent fuel sample in well controlled conditions. The slow evaporation process characterizing this experiment, stresses the preferential evaporation phenomenon: the comparison between the experimental results and the thermodynamic model predictions represents the main validation of the thermodynamic model and constitute a main outcome of this paper.

3. For the assessment of the uncertainties related to the vapor composition measurements in GDI sprays: in this case, the typical tracers concentration range found in previous GDI measurements [10] is used as an input in the model to assess the related vapor fuel compositions. The discrepancies between model and experiments observed during the validation described in the previous point are introduced to assess the impact of these differences on the fuel vapor composition estimation.

However, it is important to underline that for each of the three applications of the thermodynamic model, different hypotheses are needed to couple the model to the environment. These hypotheses, which have a significant impact mostly on the second and the third case, will be detailed later on in the paper.

\subsection{Thermodynamic model}

In this section, the thermodynamic model employed to describe the phase behavior of the multicomponent fuel is presented together with the numerical scheme employed for the calculations.

The thermodynamic model used is based on the Predictive Soave-Redlich-Kwong (PSRK) state equation. The PSRK EoS is an enhancement of the classical SRK cubic state equation [21]. This approach was 
proposed by Holderbaund and Gmehling in 1991 and it showed to be adapted to accurately describe complex system, such as strongly non-ideal mixtures (i.e. ethanol blended fuels).

In this model, the pressure $P$ is connected to volume $v$ and temperature $T$ by the classic expression of SRK equation:

$$
P=\frac{R T}{v-b}-\frac{a}{v(v+b)}
$$

Where $a$ is a parameter associated to attractive interactions and $b$ is co-volume which is the smallest accessible volume. $R$ is the universal gas constant. Equation (1) is directly used for pure compound if parameters $a$ and $b$ are defined. For a mixture containing different components, the parameters of equation of state can be calculated using the parameters of each pure component combined by the following mixing rules.

$$
\frac{a}{b R T}=\sum_{i} x_{i} \frac{a_{i}}{b_{i} R T}+\frac{1}{q_{1}}\left[\frac{G^{e x}}{R T}+\sum_{i} x_{i} \ln \left(\frac{b}{b_{i}}\right)\right]
$$

$$
b=\sum_{i} x_{i} b_{i}
$$

Where $x_{i}$ is the molar fraction of component $i$. The co-volume of the mixture is directly a linear combination of the co-volume of each compounds and the attractive term is calculated from a mixing rules based on Gibbs free energy $\left(G^{e x}\right) \cdot q_{1}$ is a parameter function of the equation of state and its value is equal to 0.64663. The Gibbs free energy used in the PSRK equation of state is the UNIFAC model which is based on a group contribution method and gives a predictive character to this equation.

The pure component parameters $a_{i}$ and $b_{i}$ are only dependent on critical properties and specific properties of the species according the following expressions:

$$
a_{i}=0.42748 \frac{R^{2} T_{c i}^{2}}{P_{c i}} \alpha(T)
$$




$$
b_{i}=0.086641 \frac{R T_{c i}}{P_{c i}}
$$

Where $T_{c i}$ and $P_{c i}$ are respectively the critical temperature and the critical pressure of component $i$. The function $\alpha(T)$ is given by:

$$
\alpha(T)=T_{r}^{C 3(C 2-1)} \exp \left[c 1\left(1-T_{r}\right)\right]^{c 2 c 3}
$$

Where $T_{r}$ is the reduced temperature $\left(T / T_{c i}\right) . C_{1}, C_{2}$ and $C_{3}$ are specific parameters which are determined empirically in order to well fit the vapor pressure of pure compound.

If the pure compounds are well defined, the equation should be used in a predictive way. The equation of state is used to calculate the phase behavior of the fluid using equilibrium calculation (flash).

\subsection{Fuel, tracers and filters selection}

For the correct application of the $2 \mathrm{~T}$-LIF the fuel composition as well as the tracers employed has to be carefully selected. The requirement of the technique and the choices performed are detailed in the following sections.

\subsubsection{Fuel surrogate definition}

As mentioned in the introduction, the fuel employed has to be transparent to the laser wavelength and non-fluorescent: commercial gasoline cannot be employed and a specific fuel surrogate is needed. Also, the surrogate fuel should be representative of a real gasoline evaporation having a similar distillation curve in order to maintain the focus of the study on real engine application. Therefore, a specific fuel physical surrogate has to be defined.

A simplified discrete model for petroleum-derived fuel is proposed to permit to track experimentally and instantaneously multiple classes of volatilities.

In our approach the surrogate is constructed with saturated hydrocarbons in order to ensure its transparency to UV laser excitation. The compounds are chosen and their proportions are tuned in order 
to obtain a mixture that reproduces the experimental distillation curve of real fuel (ASTM standards [22]). Figure 2 shows the comparison of the commercial gasoline distillation curve and the distillation curve obtained for the surrogate fuel, including modeling and experimental (ASTM distillation characterization of the formulated surrogate fuel mixture) results. The comparison has two important outputs: i) the surrogate fuel well represents the evaporation behavior of the commercial gasoline and ii) the thermodynamic model well predicts the evaporation behavior of the surrogate fuel and provides a first validation of the thermodynamic model employed. In Table 1, the composition of the gasoline surrogate is displayed together with the main physical properties of the different components. For reference ethanol properties have been added to the table.

Table 1. Composition of the gasoline surrogate and physical properties of each single component at reference conditions ( $\mathrm{T}=25^{\circ} \mathrm{C}$ and $\mathrm{p}=1 \mathrm{bar}$ ).

\begin{tabular}{|l|ccc|c|}
\cline { 2 - 4 } \multicolumn{1}{c|}{} & \multicolumn{3}{|c|}{ Gasoline surrogate } & \multirow{2}{*}{ Ethanol } \\
\cline { 2 - 4 } & n-pentane & iso-octane & n-undecane & \\
\hline Chemical Formula & $\mathrm{C}_{5} \mathrm{H}_{12}$ & $\mathrm{C}_{8} \mathrm{H}_{18}$ & $\mathrm{C}_{11} \mathrm{H}_{24}$ & $\mathrm{C}_{2} \mathrm{H}_{6} \mathrm{O}$ \\
Density $\left[\mathrm{kg} / \mathrm{m}^{3}\right]$ & 36 & 46 & 18 & $0 / 20 / 85$ \\
Normal Boiling Point $\left[{ }^{\circ} \mathrm{C}\right]$ & 621.7 & 690.3 & 737.6 & 789.1 \\
Enthalpy of vaporization $[\mathrm{kJ} / \mathrm{kg}]$ & 36.1 & 99.2 & 195.9 & 78.9 \\
\hline
\end{tabular}

\subsubsection{Tracers selection}

The tracers to be employed for the 2T-LIF experiments are selected taking into account two main aspects: Physical properties. The tracers have to be representative of different distilled fractions of the target fuel. In particular, one has to evaporate together with the light compounds of the fuel and the other together with the heavier ones. Boiling temperature is an important parameter to evaluate the volatility of a compound. However, when a tracer is dissolved in a blend its volatility also depends on the other compounds of the mixture. Han and Steeper et al. $[23,24]$ showed that the sole boiling temperature of each tracer is not sufficient to choose the tracer and the co-evaporation with the other components of the 
blend has to be taken carefully into account. The tracers-blend co-evaporation was one of the primary parameter for the tracer selection and it has been checked using the thermodynamic model.

Fluorescent emissions. To enable a spectral separation of the signals emitted, the two tracers should emit at different wavelengths with a minimum crosstalk. In this way, using a proper filtering, it is possible to collect separately the fluorescence of each tracer and therefore to perform simultaneous measurements. It is also important to avoid the co-existence of fluorescence species which interact among each other. In particular, excited-state energy transfer between aromatic and ketones species have been reported to interfere with signal quantification [25].

After a careful screening of the available information in the literature, the tracers selected for this study are difluorobenzene $(D F B)$ and 1-methylnaphtalene $(1 M N)$. The DFB represents the light compounds of the tested fuel and the $1 M N$ the heavy compound of the fuel. The physical properties of the two tracers are presented in Table 2 and their effective representativeness of the respective volatility classes will be demonstrated by the experiments carried out in this work. It is important to note that $1 \mathrm{MN}$ boiling point is slightly higher than the maximum of the distillation curve of gasoline (c.f. Figure 2). In the results section it will be proved that when the $1 \mathrm{MN}$ is added in very low concentrations $(\sim 0.15 \%)$, the tracer co-evaporates together with the heavier fractions of the Gasoline. These two tracers features a good chemical stability and a very high quantum yield also at high temperatures (e.g. 900K) [20,26-29]. Their emission spectrum is well separated enabling independent filtering of the two signals (Figure 3 ) limiting the cross-talk. The high quantum yield of both tracers provide sufficient fluorescent signal also at very low concentration as shown by Itani et al. ( 0.15\% (mass) [10]). From a thermodynamic point of view, this aspect enables to not modify physical properties of the mixture.

The two tracers have been widely characterized in previous studies investigating the effect of the temperature and pressure on fluorescent emissions and it is available in the literature $[18,30,31]$. The photo-physics related to this process is described in details in [26]. This information is therefore available for future quantitative interpretation of the 2T-LIF signal. 
Despite their importance for future GDI application of the diagnostics, these features are not relevant to the present paper, in which the LIF measurement are performed at constant ambient temperature and pressure following a specific in-situ calibration. Therefore detailed information is referred to the cited bibliography. The suitable thermodynamic characteristics together with the optimal fluorescent characteristics (spectrally well separated emissions and low temperature dependence) make of these tracers good candidates for GDI applications. In this work, the validation of the thermodynamic model will be therefore carried out blending the surrogate fuel presented in the previous section with $1 \mathrm{MN}$ and DFB.

Table 2. Physical properties of the tracers. The properties are presented at standard reference conditions $\left(T=25^{\circ} \mathrm{C}, p=\right.$ $\left.p_{\text {atm }}\right)$

\begin{tabular}{|r|c|c|}
\hline & DFB & 1MN \\
\hline Representative of & Lighter fuel compounds & Heavier fuel compounds \\
\hline Chemical Formula & $\mathrm{C}_{6} \mathrm{H}_{4} \mathrm{~F}_{2}$ & $\mathrm{C}_{11} \mathrm{H}_{10}$ \\
\hline Normal Boiling Point $\left[{ }^{\circ} \mathrm{C}\right]$ & 88.8 & 244.7 \\
\hline Density $\left[\mathrm{kg} / \mathrm{m}^{3}\right]$ & 1164.272 & 1016.43 \\
\hline Enthalpy of vaporization $[\mathrm{kJ} / \mathrm{kg}]$ & 312.97 & 405.15 \\
\hline
\end{tabular}

\subsection{Fuel vapor composition measurement in a GDI spray}

The 2T-LIF provides quantitative information on local tracer mass fraction. As consequence of that, the tracers' ratio $\left(T_{R}\right)$ is calculated by applying the definition below:

$$
T_{R}=\frac{Y_{1 M N}}{Y_{D F B}}
$$

being $Y_{1 M N}$ and $Y_{D F B}$ the mass fraction of respectively $1 M N$ and $D F B$.

$270 T_{R}$ has been used in previous studies to indicate qualitatively heterogeneities in the vapor fuel composition

271 [10]. In this work, the thermodynamic model enables to establish a relationship between the ratio 272 experimentally measured, and the fuel vapor composition. 
273 To link the 2T-LIF data to the fuel vapor composition two possibilities approaches can be identified. The 274 first, if the LIF-based imaging data are to be compared with CFD simulations, it may be possible to include 275 the tracers in the simulation's evaporation model, which would then allow a direct comparison to the experimental data to evaluate the accuracy of that particular evaporation model. The downside of this approach is that a model may differ in the accuracy with which it predicts major fuel components vs. subpercent trace species. On the other hand another simplified approach is proposed in this paper which need to make some assumptions about the fuel evaporation process. The vapor fuel composition calculation proposed is based on the following hypotheses:

1. It is assumed that the evaporation at the liquid-vapor interface is at equilibrium

2. The evaporation process is considered to be slow compared to the mass diffusion of the components within the droplet, and therefore the liquid phase is considered well mixed.

As a consequence of that, different scenarios are assumed depending on the value of $T_{R}$.

- $T_{R}=1$. In this case, no preferential evaporation is observed and the composition is considered equal to the original fuel composition.

- $T_{R}<1$. The high volatility tracer (DFB) prevails in the mixture. This mixture is considered to be originated by the first evaporated fractions of a droplet, which completed its evaporation elsewhere. The composition of this mixture is calculated by finding the value of evaporated mass fraction $\left(M_{\text {evap }}\right)$ at which the ratio of the integral of the distillation curve of the tracers' is equal to $T_{R}, M_{\text {evap }, 0}:$

Where, $y_{1 M F}$ and $y_{D F B}$ indicate the distilled fractions of $1 M F$ and DFB. of each component $i$ between 0 and $M_{\text {evap, } 0}$

$$
Y_{i}=\int_{0}^{M_{\text {Evap }, 0}} y_{i} d M_{\text {Evap }}
$$


- $T_{R}>1$. The low volatility tracer $(1 \mathrm{MN})$ prevails in the mixture. The mixture is considered to be originated by the evaporation of a droplet which lost its lighter fractions elsewhere. In this case, $\mathrm{M}_{\mathrm{evap}, 0}$ is found by calculating the integral of the distillation curve between $M_{\text {evap }, 0}$ and 1:

$$
\frac{\int_{M_{\text {Eva }, 0}}^{1} y_{1 M F} d M_{\text {Evap }}}{\int_{M_{\text {Evap }, 0}}^{1} y_{D F B} d M_{E v a p}}=T_{r}
$$

In the same fashion, the mass fraction of each component $Y_{i}$ is obtained by integrating the distillation curves of each component $i$ between $M_{\text {evap }, 0}$ and 1

$$
Y_{i}=\int_{M_{E v a p, 0}}^{1} y_{i} d M_{E v a p}
$$

In first approximation these hypotheses are applicable for a GDI spray, where the relatively low chamber temperature and gas density causes a slow evaporation process [32].

The relationship between $T_{R}$ and vapor composition obtained with these hypotheses and on the results of the thermodynamic model is presented in Figure 4. The results refer to the composition of the gasoline surrogate described in Table 1 at atmospheric pressure for a tracer concentration of $0.15 \%$ (in mass). This map indicates on the $x$-axis the tracers' concentration ratio, and, on the $y$-axis, the mass composition of the vapor. Each color represents a different compound of the surrogate, while the tracers, which are used in a very low concentration, are neglected in the map.

Also, the composition map describes a range of variation of $T_{R}$ obtained by considering a complete theoretical evaporation process. However, the tracers' ratio range measurable in the reality depends on the sensitivity of the setup and of the cameras employed. For reference, based on the observations presented by Itani et al. $[10,18]$ a "practical range" is identified and indicated on Figure 4 by considering the maximum $T_{R}$ variations measured in their experiments. 


\section{Experimental setup}

An experimental apparatus was put in place to provide phase equilibrium of tracers and validation data for the thermodynamic model, with the objective of providing fundamental understanding of preferential evaporation in multicomponent fuel and to validate the thermodynamic model.

The experimental setup involves a heated bubbler to evaporate gradually and in a finely controlled way a certain volume of fuel; a $\mathrm{N}_{2}$ dilution system to reduce the partial pressure of the fuel vapor extracted and avoid condensation along the connecting pipeline; an optical cell, where the tracers' concentration in the diluted fuel vapor is measured by means of laser induced fluorescence.

The fuel is evaporated gradually in a heated cell where $\mathrm{N}_{2}$ is bubbled through the liquid phase. The $\mathrm{N}_{2}+$ vapor fuel extracted from the cell flows through a second cell at constant temperature where the $2 \mathrm{~T}$-LIF technique is applied. The measurement can provide the relationship between the total evaporated mass and the vapor tracers' concentration during the whole evaporation process. This relationship will be the reference to be used for the validation of the thermodynamic model.

The details of the setup and of the data analysis are presented in the following section.

\subsection{Experimental apparatus}

The experimental apparatus is presented schematically in Figure 5 and it is composed of three main parts:

1. Evaporation cell. The aim of the evaporation cell is to cause the evaporation of the volume of the tested fuel in a controlled and repetitive way. The cell is partially filled with a volume of the studied fuel $V_{0}(\sim 20 \mathrm{ml})$. A bubbler feeds a constant flow rate of nitrogen $\left(\dot{m}_{1}\right)$ through the cell to ensure the formation of saturated fuel vapor in the upper part of the chamber where the outlet is placed. A set of heating resistances heats homogeneously the evaporation cell, while a control system sets the heating power to increase gradually and in a controlled way the temperature of the cell. The volume of liquid fuel is monitored thanks to an optical access to the evaporation chamber that enables to measure the height $H$ of remaining fuel; the corresponding mass is then calculated 
taking into account the density corresponding to the instantaneous temperature of the fuel $\left(T_{1}\right)$ which is measured directly through a thermocouple immerged in the liquid fuel.

2. Heated pipeline. The $\mathrm{N}_{2}$, saturated with fuel vapor, exits the evaporation chamber, and passes through a heated pipeline connecting the evaporation cell to the imaging cell. To prevent the recondensation of the fuel vapor along the pipe walls, the pipe is heated at a temperature $\left(T_{\text {pipe }}\right)$ higher than $T_{1}$. Moreover, a second constant stream of heated nitrogen $\dot{m}_{2}$ is fed, being the mass flow rate $\dot{m}_{2}$ a multiple of $\dot{m}_{1}\left(\dot{m}_{2}=\mathrm{n} \dot{m}_{1}\right)$ to reduce the concentration of fuel vapor. The value of $\mathrm{n}$ is approximately 20 . The dilution has the two following advantages: i) it further reduces the Appendix.

All the system is designed to perform tests up to a pressure of 15 bar. The nitrogen flow $\left(\dot{m}_{1}\right.$ and $\left.\dot{m}_{2}\right)$ is controlled by means of two automatic flow regulators upstream of the system, while the pressure of the system $\left(p_{\text {sys }}\right)$ is controlled by manually adjusting the aperture of a valve downstream of the LIF cell (Figure 5). The complete details of the optical setup and of the data processing are presented in the 
Figure 6 presents a sample of the results obtained by the analysis. The results present the tracers' distilled fraction at each step of the fuel evaporation, indicating on the abscissa the Evaporated Mass Fraction $(E M F)$. In accordance to the physical properties of the tracers, DFB starts evaporating at the beginning of the evaporation process and continues until the EMF is approximately 0.8 . The $1 M N$, with higher boiling point, starts evaporating for EMF $>0.7$ and it continues until the end of the process. Figure 6 also shows the comparison between three repetitions of the test: the results of the methodology appear precise and robust, and in the remnant of the paper only the average of the three repetitions will be presented. It is worth underlining that for all the tests performed a certain dispersion of the results was observed at the beginning and at the end of the evaporation. The authors consider that data gathered at the beginning and at the end of the experiment are less accurate due to different reasons. At the beginning of the experiments the nitrogen flow is activated in the bubbler and in the dilution line: this process might take few minutes before reaching the set-point values, especially at higher test pressures and therefore the related data could be slightly biased in this period. On the other hand, at the end of the experiments the measure of the remaining volume becomes more difficult due to the increasing impact that the reading uncertainty $\left(+/-20 \mathrm{~mm}^{3}\right)$ has on the total volume measured. For this reason for $E M F<0.1$ and EMF> 0.9 interval of the evaporation diagrams are normally not considered for the comparisons and the results will be considered only in the $10-90 \%$ mass fraction interval.

\subsection{Test matrix}

The experimental campaign has the double objective of investigating the effect of parametric variations on preferential evaporation phenomenon and to provide data to validate the thermodynamic model.

The effect of the evaporation pressure was tested carrying out the tests at 1 bar (atmospheric), 5 and 10 bar. The fuel composition effect was also investigated by adding progressively ethanol to the surrogate fuel. Apart from the standard gasoline surrogate defined in Table 1, two further surrogate/ethanol blends were tested featuring 20 and $85 \%$ in volume of ethanol. In the remnant of the paper standard gasoline surrogate will be referred as E00, while the $20 \%$ and $85 \%$ ethanol blends will be referred as E20 and E85. 


\section{Experimental results and model validation}

394

In this section, the experimental results are presented and compared to the results provided by the thermodynamic model. The effects of parametric variations in system pressure and ethanol content are discussed.

\subsection{Gasoline surrogate at atmospheric pressure}

Figure 7 presents the results obtained for the evaporation of gasoline surrogate (E00) at atmospheric pressure. Experimental and modeling results indicate a significant separation between the evaporation of the two tracers: $D F B$ evaporates together with the lighter fraction of the surrogate and then gradually its concentration in the vapor decreases. The DFB fluorescent intensity (and therefore DFB concentration) becomes lower than the noise level at approximately $80 \%$ of the evaporated fuel mass. On the contrary, $1 \mathrm{MN}$ fluorescence is detected approximately when the EMF exceeds 0.6 and it evaporates together with the heavier fuel distilled fraction.

This first result confirms that the tracers chosen are capable of representing the different volatility class of the surrogate fuel, with $D F B$ being representative of the light compounds, while $1 \mathrm{MN}$ is representative of the heavier ones.

When the tracers evaporation curves are compared to the ones provided by the model, the evaporation behavior of the two tracers is globally well represented by the model predictions along the whole evaporation process. In particular, the co-evaporation process of $1 \mathrm{MN}$ is well represented: even though the boiling point of this tracer is higher than the one of the heaviest component of the surrogate, it starts evaporating well before the end of the evaporation process.

\subsection{Effect of ambient pressure}

Figure 8 presents the experimental results (left hand side) and model predictions (right hand side) at different ambient pressures for the gasoline surrogate (E00). Despite the increase in $p_{\text {sys }}$ the comparison indicates that the preferential evaporation phenomenon remains substantially similar: the DFB evaporates 
evenly until $80 \%$ of the evaporated mass fraction and the $1 \mathrm{MN}$ curve is characterized by a prominent peak rising at $E M F>0.9$. More in details, both, experiments and model, show qualitatively similar variation in the evaporation profiles when $p_{s y s}$ is increased: a flattening of the DFB evaporation profile and its persistence also during the last phase of the fuel evaporation. Also, a progressive sharpening of the $1 \mathrm{MN}$ peak at the end of the evaporation is observed. Although some discrepancies can be observed between model and experimental results, it can be concluded that, globally, it captures the changes in the shape of the evaporation of the tracers.

Figure 9 shows more results from the thermodynamic model, indicating how the system pressure affects the evaporation of the different components of the surrogate. In particular it can be observed that it has a non-negligible impact in homogenizing the evaporation of the components. E.g. n-pentane persists in the liquid up to the end of the evaporation and n-undecane starts evaporating at a low rate since the beginning of the process. In a practical way, this result indicates that increasing the system pressure can potentially reduce the preferential evaporation effect.

\subsection{Effect of Ethanol}

431 The effect of the ethanol addition on the tracers evaporation is presented in Figure 10 showing for each 432 ethanol blend the results obtained at ambient pressure (left column) and at 10 bar (right column).

433 Model and experimental results indicate that the addition of ethanol has a non-negligible impact on the evaporation of the fuel. In particular the variation in the shape of the DFB and $1 \mathrm{MN}$ distillation curves indicates that the evaporation of the light and heavy compounds happens in the three cases in a different way.

437 For $E 85$ case the $1 M N$ evaporation is observed mainly during the last $5 \%$ of the fuel mass fraction 438 evaporation. Even though the measurements concerning the last $10 \%$ of evaporated fuel are characterized by low accuracy, both, experiments and models well capture the modification in the evaporation curves of DFB and 1MF induced by the ethanol addition. The effect of ethanol is well represented by the model, at least in a qualitative way. In particular, results indicate that increasing the

442 ethanol content causes $1 \mathrm{MN}$ to evaporate progressively at higher values of EMF. However, the trend for DFB is not as simple: while for E20, DFB evaporation is delayed when compared to E00, for E85 DFB 
evaporate at lower values of EMF. In Figure 11 more results from the thermodynamic model are presented showing the vapor concentration predicted for each distilled fraction (the tracer composition is neglected). These results show that the evaporation of the fuel changes radically when passing from E20 to E85. Consistently with its lower boiling temperature $n$-pentane is the first fraction to evaporate for the three cases. Following the same logic, n-undecane is the last component to evaporate (boiling point 195 ${ }^{\circ} \mathrm{C}$ ). On the contrary, iso-octane evaporates after ethanol for E20 and before in E85. This behavior can be related to the formation of an azeotrope among ethanol forms with lighter compounds for E85 which links together the evaporation of $n$-pentane, iso-octane and ethanol. This behavior is related to the physicchemical affinity between ethanol, iso-octane and n-pentane. Similar effects have been described in [13]. More in details, it can be observed as for E20 the azeotrope causes a similar evaporation among isooctane and ethanol up to the complete evaporation of the latter. After this point the ethanol an evident change of behavior of iso-octane can be observed (c.f. red arrow in Figure 11 ). On the contrary, for E85, due to the higher presence of ethanol, the iso-octane evaporates to completion before the ethanol, changing radically the shape of its evaporation curve.

A closer look to Figure 11 and Figure 10 shows that the modification is the shape of the curved observed for DFB follow quite closely the ones observed for iso-octane. This fact is also underlined by the appearance of a peak on the DFB evaporation curve observed for E20 (c.f. red arrow in Figure 10). This peak corresponds to the peak in iso-octane evaporation observed for iso-octane (c.f. red arrow in Figure 11). This aspect underlines how the thermodynamic model is important to understand the tracers' results: in fact by taking only into account the boiling point, one might expect DFB to be equally representative of Ethanol and iso-octane. These results, as others in the literature $[16,18,32]$, show clearly that more complex interactions need to be taken into account.

Figure 11 also provides another important indication about the lower volatility classes of the surrogate (nundecane). Probably due to the high difference in boiling point, n-undecane does not co-evaporate with the azeotrope mentioned above, and it is indicate to evaporate to completion only when the last fraction of ethanol is evaporated. In a more practical sense, an important ethanol blending in commercial gasolines (e.g. E85), while homogenizing the evaporation of the light and medium volatility class of gasoline might cause a higher segregation of the heavier compounds. 
Ethanol, due to its higher evaporation enthalpy, is in general considered to delay sprays evaporation due to its high latent heat [15]. However, the results observed in this section indicate that, if the well mixed hypothesis of the liquid fuel is verified, as it is reasonable for the evaporation experiment, ethanol evaporate well before the heavier volatility compounds, causing less co-evaporation of the heavier fractions (e.g. n-undecane).

\subsection{Vapor composition calculation and accuracy estimation}

To provide a further insight about the accuracy of the methodology proposed the coupling between the thermodynamic model and the results from the $2 \mathrm{~T}$-LIF measurements are analyzed investigating the impact that the discrepancies between experimental and modeling results presented in section 4 , have on the global accuracy of the technique.

Instead of calculating the complete uncertainty analysis of the evaporation experiments, which analysis would go beyond the scope of this section, the deviation between the model and the experimental results has been considered as a first order estimation of the error of the model predictions. This deviation has been employed to estimate how the error in the thermodynamic model prediction on tracers' evaporation, propagates to the vapor fuel calculation. In this way: fixing the relationship between the vapor composition and the fuel evaporated mass, the map presented in Figure 4 has been re-calculated in two different ways 1) using the $T_{R}$ obtained by the model simulation (as done for Figure 4) and 2) using the $T_{R}$ obtained experimentally.

In Figure 12 the comparison is presented for the different fuels tested (from top to bottom E00, E20 and E85) and for two $p_{\text {sys }}$ (from left to right 1 and 10 bar). The comparison shows that for all the cases, the fuel vapor concentration is obtained with accuracy also when using the experimental input. In the practical range the difference is in general lower than $2 \%$ and never above $5 \%$. This means that despite the discrepancies observed in the evaporation experiment between model and experimental results the impact on the vapor fuel composition calculation are expected to be acceptable $(<5 \%)$ in the relevant range of measurements. 


\section{Summary and Conclusions}

This paper presents a novel approach for the quantitative interpretation of 2T-LIF experiments, making of it a powerful optical diagnostic to study preferential evaporation in GDI engines.

The methodology combines a state-of-the art optical diagnostic (2-tracers laser induced fluorescence) with a numerical model, and enables to assess the effects of preferential evaporation in a multicomponent and eventually to perform quantitative measurement of vapor-phase fuel composition. An optically transparent surrogate for commercial gasoline has been found which replicates closely the distillation curve of the real fuel.

This paper, a part from presenting the methodologies, presents the results of an experiment that, at the same time, investigates the effect of boundary conditions on preferential evaporation process and assesses the accuracy of the methodology proposed. The main outcomes are:

- An increase in system pressure increases the co-evaporation among the different volatility class.

- The addition of ethanol was observed to have a complex effect on fuel evaporation. When added in lower concentrations (E20) it is observed to evaporate before isooctane as expected considering the lower boiling point. However, for E85, where ethanol is the main component of the blend it causes n-pentane and iso-octane to evaporate to completion before ethanol. At the same time for E85 the evaporation of the n-undecane is segregated and the end of the evaporation curve.

- Ethanol is observed to form an azeotrope with iso-octane and n-pentane due to their physicalchemical affinity changing significantly their evaporation curves.

- The two tracers proposed, have been found to co-evaporate together with the light-medium volatility class of gasoline (difluorobenzene) and the heavy ones (1-methylnaphtalene). Finally, the impact of hypothetic errors of the thermodynamic model on the vapor fuel composition calculation was assessed, by using as error indication the deviation between experimental and modeling results. The analysis indicates that, the impact on the vapor fuel calculation for the conditions relevant to engine application were acceptable $(<5 \%)$. 


\section{Acknowledgement}

524 FVV funding is acknowledged (agreement 6011101, Bioptic2 project). Also the technical expertise of 525 Jerome Cherel and Vincent Ricordeau are greatly acknowledged as well as the scientific discussions with 526 Hubert Baya Toda. Fredric Grisch and Bjorn Rossow are also acknowledged for the scientific discussion 527 and the tracer characterization data provided.

\section{Symbology}

529 1MN: 1-methylnaphtalene

530 2T-LIF: two-tracer laser induced fluorescence

$531 \quad a, b, a_{i}, b_{i}$ : constants

$532 \quad \mathrm{C}_{1}, \mathrm{C}_{2}, \mathrm{C}_{3}$ : constants

533 DFB: difluorobenzene

534 E00: gasoline surrogate

535 E20: gasoline surrogate + ethanol 20\% (vol)

536 E85: gasoline surrogate + ethanol 85\% (vol)

537 EMF: evaporated mass fraction

$538 \quad E_{\text {laser: }}$ laser pulse energy

539 F.S.: camera sensor full scale

540 GDI: gasoline direct injection

$541 I_{1}, I_{2}$ : average counts measured by the camera for the area $A_{1}$ and $A_{2}$

$542 L_{1}, L_{2}$ : Fluorescent intensity measured in the portion of the sensor $A_{1}$ and $A_{2}$

$543 \mathrm{M}_{1}, \mathrm{M}_{2}$ : quantity proportional to the mass of tracer passed through in the imaging cell during the 544 integration interval

$545 \mathrm{~N}$ : average noise counts (measured in the area $A_{N}$ )

546 p: pressure (generic)

$547 \quad p_{\text {sys }}$ : pressure of the experimental apparatus 
R: universal gas constant

549 SRK: Soave-Redlich-Kwong.

550 T: temperature (generic)

$551 \quad \mathrm{~T}_{1}$ : Temperature measured within the bubbler

$552 \mathrm{~T}_{3}$ : Temperature measured within the imaging cell

$553 \quad \mathrm{~T}_{\mathrm{R}}$ : Tracers' concentration ratio

$554 \mathrm{~T}_{\text {pipe: }}$ : temperature of the connecting pipe

$555 \quad V_{\text {fuel }}$ : volume of the liquid fuel in the evaporation cell

556 v: specific volume (generic)

\section{References}

558 [1] Gupta HN. Fundamentals of internal combustion engines. PHI Learning Pvt. Ltd; 2012.

559 [2] Dober G, Tullis S, Greeves G, Milovanovic N, Hardy M, Zuelch S. The impact of injection strategies 560 on emissions reduction and power output of future diesel engines. SAE SP 2008;2183:183.

[3] Baumgarten C. Mixture formation in internal combustion engines. Springer Science \& Business Media; 2006.

563 [4] Park SH, Yoon SH, Lee CS. Effects of multiple-injection strategies on overall spray behavior, combustion, and emissions reduction characteristics of biodiesel fuel. Applied Energy 2011;88(1):8898.

[5] Dec JE. Advanced compression-ignition engines-understanding the in-cylinder processes. Proceedings of the Combustion Institute 2009;32(2):2727-42.

[6] Bandel W, Fraidl GK, Kapus PE, Sikinger H. The Turbocharged GDI Engine: Boosted Synergies for High Fuel Economy Plus Ultra-low Emission 2006;2006-01-1266.

[7] Musculus MPB, Miles PC, Pickett LM. Conceptual models for partially premixed low-temperature diesel combustion. Progress in Energy and Combustion Science 2013;39(2-3):246-83.

[8] Zhang L, Kong S-C. Modeling of multi-component fuel vaporization and combustion for gasoline and diesel spray. Chemical Engineering Science 2009;64(16):3688-96. 
574 [9] Zigan L, Schmitz I, Flügel A, Wensing M, Leipertz A. Structure of evaporating single- and multicomponent fuel sprays for 2nd generation gasoline direct injection. Fuel 2011;90(1):348-63.

[10] Itani LM, Bruneaux G, Di Lella A, Schulz C. Two-tracer LIF imaging of preferential evaporation of multi-component gasoline fuel sprays under engine conditions. Proceedings of the Combustion Institute 2015;35(3):2915-22.

[11] Kitano T, Nishio J, Kurose R, Komori S. Evaporation and combustion of multicomponent fuel droplets. Fuel 2014;136:219-25.

[12] Al Qubeissi M, Sazhin SS, Crua C, Turner J, Heikal MR. Modelling of biodiesel fuel droplet heating and evaporation: Effects of fuel composition. Fuel 2015;154:308-18.

[13] Bader A, Keller P, Hasse C. The influence of non-ideal vapor-liquid equilibrium on the evaporation of ethanol/iso-octane droplets. International Journal of Heat and Mass Transfer 2013;64:547-58.

[14] Storch M, Hinrichsen F, Wensing M, Will S, Zigan L. The effect of ethanol blending on mixture formation, combustion and soot emission studied in an optical DISI engine. Applied Energy 2015;156:783-92.

[15] Storch M, Pfaffenberger A, Koegl M, Will S, Zigan L. Combustion and Sooting Behavior of SparkIgnited Ethanol-Isooctane Sprays under Stratified Charge Conditions. Energy Fuels 2016;30(7):6080-90.

[16] Krämer H, Einecke S, Schulz C, Sick V, Nattrass Steve R., Kitching John S. Simultaneous Mapping of the Distribution of Different Fuel Volatility Classes Using Tracer-LIF Tomography in an IC Engine. SAE Technical Paper 1998;982467.

[17] Wyman C. Handbook on Bioethanol: Production and Utilization. 1st ed. New York: Routledge; 1996.

[18] Itani L. Development and application of optical diagnostic techniques for assessing the effects of preferential evaporation of multi-component fuels under engine-relevant conditions, $\mathrm{PhD}$ thesis Cotoutelle Duisburg University/IFPEN; 2015.

[19] Williams B, Ewart P, Wang X, Stone R, Ma H, Walmsley H et al. Quantitative planar laser-induced fluorescence imaging of multi-component fuel/air mixing in a firing gasoline-direct-injection engine: Effects of residual exhaust gas on quantitative PLIF. Combustion and Flame 2010;157(10):1866-78. 
601 [20] Kashdan JT, Docquier N, Bruneaux G. Mixture preparation and combustion via LIEF and LIF of combustion radicals in a direct-injection, $\mathrm{HCCl}$ diesel engine. SAE International 2004;2004-01-2945.

[21] Holderbaum T, Gmehling J. PSRK: A group contribution equation of state based on UNIFAC. Fluid Phase Equilibria 1991;70(2):251-65.

[22] American Society for Testing and Materials. Annual Book of ASTM Standards.

[23] Han D, Steeper RR. Examination of Iso-octane/Ketone Mixtures for Quantitative LIF Measurements in a DISI Engine. In: SAE International; 2002.

[24] Steeper R, Zilwa S de, Fayoux A. Co-Evaporative Tracer-PRF Mixtures For LIF Measurements in Optical HCCI Engines. In: SAE International; 2005.

[25] Koban W, Schorr J, Schulz C. Oxygen-distribution imaging with a novel two-tracer laser-induced fluorescence technique. Applied Physics B 2002;74(1):111-4.

[26] Schulz C, Sick V. Tracer-LIF diagnostics: quantitative measurement of fuel concentration, temperature and fuel/air ratio in practical combustion systems. Progress in Energy and Combustion Science 2005;31(1):75-121.

[27] Devillers R, Bruneaux G, Schulz C. Investigation of toluene LIF at high pressure and high temperature in an optical engine. Applied Physics B: Lasers and Optics 2009;96(4):735-9.

[28] Kaiser SA, Long MB. Quantitative planar laser-induced fluorescence of naphthalenes as fuel tracers. Proceedings of the Combustion Institute 2005;30(1):1555-63.

[29] Lind S, Retzer U, Will S, Zigan L. Investigation of mixture formation in a diesel spray by tracer-based laser-induced fluorescence using 1-methylnaphthalene. Proceedings of the Combustion Institute $2017 ; 36(3): 4497-504$.

[30] Benzler T, Dreier T, Schulz C. UV absorption and fluorescence properties of gas-phase pdifluorobenzene. Applied Physics B 2017;123(1):39.

[31] Benzler T, Faust S, Dreier T, Schulz C. Low-pressure effective fluorescence lifetimes and photophysical rate constants of one- and two-ring aromatics. Applied Physics B 2015;121(4):549-58.

[32] Kranz P, Kaiser SA. LIF-based imaging of preferential evaporation of a multi-component gasoline surrogate in a direct-injection engine. Proceedings of the Combustion Institute 2018. 
In this section the details of the optical setup and data processing are presented.

\subsection{Optical setup}

The laser beam employed for the 2T-LIF was the fourth harmonic of the pump wave of an Nd:YAG laser (266 nm). The maximum output of each laser beam was about $60 \mathrm{~mJ}$ and was modulated along the full range from 0 to $100 \%$ of the total power to avoid camera saturation using a beam attenuator (AltechnaWatt Pilot). The beam energy corresponding to each fluorescence image was measured and recorded using a beam sampler reflecting $10 \%$ of the beam intensity to a high-speed power meter. The laser fluence in the test section was always kept below $0.7 \mathrm{~mJ} / \mathrm{mm}^{2}$ assuring to remain in a linear fluorescence regime $[30,31]$.

638 The simultaneous detection of the fluorescent signal obtained by the two tracers was performed by means 639 of an intensified CCD camera (Princeton instrument - Pimax) fitted with a stereoscope or image-doubler.

640 The stereoscope is a commercial device (provided by LaVision) and it enables to project two times the 641 images "seen" by the two input channels on two different portion of the camera's sensor. The sample stereoscopic image presented in Figure 13 shows the LIF window, and a ruler placed within the chamber

643 along the laser beam path. Each of the stereoscope channels is fitted with a different filter as defined in

644 2.3.2, to collect separately the fluorescence signal of 1-methylnaphtalene $(370 \pm 18 \mathrm{~nm})$ and di645 fluorbenzene $(280 \pm 10 \mathrm{~nm})$. The filters enable to collect separately the signal from the two tracers with a negligible cross talk (c.f. Figure 3)

\subsection{Test Procedure}

648 The surrogate fuel (already doped with the tracers and stored at about $-10^{\circ} \mathrm{C}$ ) is poured into the 649 evaporation cell which temperature is kept at $-5{ }^{\circ} \mathrm{C}$ thanks to a refrigeration system. After closing the 650 evaporation cell, the nitrogen start flowing through the bubbler and through the dilution system and at the 651 same time the 2T-LIF system starts its acquisition. The $\mathrm{N}_{2}$ mass flow rate is kept constant by two mass 
flow rate meter placed upstream of the circuit. The laser starts pulsing at its working frequency $(10 \mathrm{~Hz})$, and the intensified LIF stereoscopic images are acquired at a reduced rate $(0.2 \mathrm{~Hz})$. For each LIF image also the following data are recorded:

- Temperatures of the system $T_{1}, T_{\text {pipe }}, T_{3}$ (see Figure 5 ).

- Fuel height in the evaporation cell $\mathrm{H}$, converted into volume left $V_{\text {fuel. }}$ A CCD camera is used to monitor the level of the fuel in the evaporation cell. An automatic processing algorithm is employed to obtain the corresponding fuel volume. In order to improve the accuracy of the volume measurement, the nitrogen flow to the bubbler is stopped shortly before the acquisition of the image $(0.2 \mathrm{~s})$ for a short time $(0.25 \mathrm{~s})$. This interruption of the bubbler flow is not considered to affect the nitrogen mass flow measurement since this process was periodic $(0.2 \mathrm{~Hz})$ and the duration of the interruption was short relatively to the period.

- Laser pulse energy $E_{\text {laser. }}$ The laser pulse energy is measured inserting a beam-sampler before the test chamber that directs part of the laser beam towards a laser energy-meter.

The data is acquired until the complete evaporation of the fuel. In order to have a good measurement precision, the fuel is evaporated gradually, and the whole process lasts 1-1.5h.

\subsection{Image processing and data analysis}

The images collected by the camera during the fuel evaporation were analyzed to establish a relationship between the evaporation of the two tracers and the evaporation of the fuel.

Each LIF image was analyzed in the following way:

I. The signal recorded by the camera for each channel is evaluated by averaging the pixel counts in the interrogation areas indicated in Figure $14\left(\mathrm{I}_{1}\right.$ and $\left.\mathrm{I}_{2}\right)$, which correspond to the same part of the chamber.

II. The average counts numbers corresponding to each interrogation area are transformed in a value proportional to the photons reaching the sensor $\left(L_{1}\right.$ and $\left.L_{2}\right)$, by taking into account the 
background noise, evaluated for each image in an area (indicated as $A_{N}$ in Figure 14) where no fluorescence signal is observed $(N)$.

$$
L_{1}=\frac{I_{1}-N}{F . S .-N}, \quad L_{2}=\frac{I_{2}-N}{F . S .-N}
$$

680

681

682

being F.S. the full scale of the sensor.

III. The LIF signals are normalized to the measured laser pulse energy $E_{\text {laser. }}$ The values obtained $\left(L_{n 1}\right.$ and $\left.L_{n 2}\right)$ are proportional to the tracer mass concentration in the visualization cell.

$$
L_{n 1}=\frac{L_{1}}{E_{\text {laser }}}, \quad L_{n 2}=\frac{L_{2}}{E_{\text {laser }}}
$$

IV. As the gas flowing though the cell is mainly composed by nitrogen, the global mass flow through the LIF cell can be assumed as constant. Therefore, the integral of $L_{1, n}$ and $L_{2, n}$ on time is proportional to the tracer evaporated mass. This value is calculated as,

$$
M_{1} \propto \int_{t_{1}}^{t_{2}} L_{1, n} d t \quad, \quad M_{2} \propto \int_{t_{1}}^{t_{2}} L_{2, n} d t
$$

V. The mass of fuel evaporated at each time interval (determined through level measured in the evaporating cell) can therefore be related to the tracer evaporated masses $M_{1}$ and $M_{2}$. Once normalized with reference to the total initial fuel mass, the curves shown in Figure 6 are obtained. On the $\mathrm{x}$-axis the fuel evaporated mass fraction, while on the $\mathrm{y}$-axis the normalized distilled fraction for each tracer is presented. The integral of each curve on the fuel evaporated mass fraction is the unity.

It is important to underline that considering the constant pressure and temperature condition in the imaging chamber, the signal calibration is based on the normalization for the total tracer mass blended in the fuel. Therefore the results are not dependent on fluorescent properties of the tracers.

\section{List of captions}

\footnotetext{
Figure 1. Scheme of the workflow for the quantitative measurement of fuel vapor composition.
} 

the areas in light colors [18]. measurements of the GDI application is indicated by the red dashed lines.

Figure 5. Schematic of the experimental validation setup.

Figure 6. Sample output from the data processing. The relationship between the distilled fraction of each tracer and the fuel evaporated mass fraction is presented. E00, $p_{s y s}=1 \mathrm{bar}$. The gray areas represents the regions of low experimental accuracy.

Figure 7. Experimental (dashed lines) and modeling (solid lines) results. Tracers' distilled fraction during the evaporation of the fuel. The gray areas represents the regions of low experimental accuracy. E00, $p_{s y s}=1 \mathrm{bar}$ of ambient pressure on the evaporation of E00.

Figure 10. Effect of ethanol addition on the evaporation of the surrogate fuel. Experimental results and model predictions.

Figure 11. Evaporation of the different fuel compounds. E00 (left), E20 (center) and E85 (left) at ambient pressure.

Figure 12. Fuel vapor composition obtained using modeling (solid lines) and experimental results (dashed lines). From top to bottom E00, E20 and E85. $p_{s y s} 1$ bar (left) and 10 bar (right). The practical range for the 2T-LIF application is indicated in red dashed lines. stereoscope.

Figure 14. Sample 2T-LIF image. The fluorescence signal obtained in the two channels along the laser beam path is displayed. The signal evaluation areas are indicated by the green squares. 


\section{List of figures}

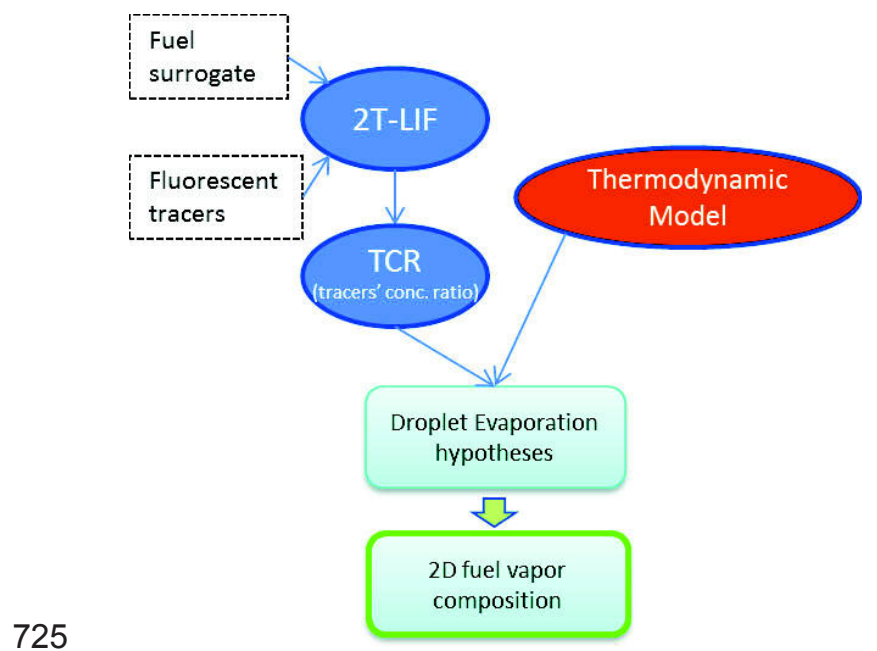

726

Figure 1

727

728

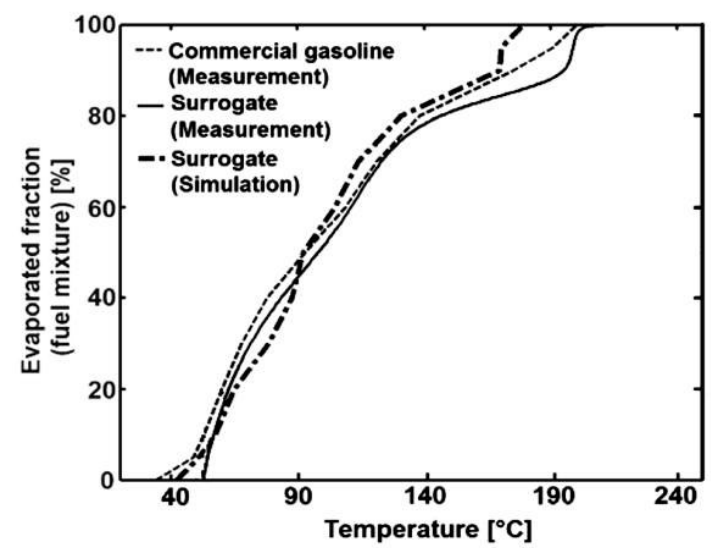

729 Figure 2

730 


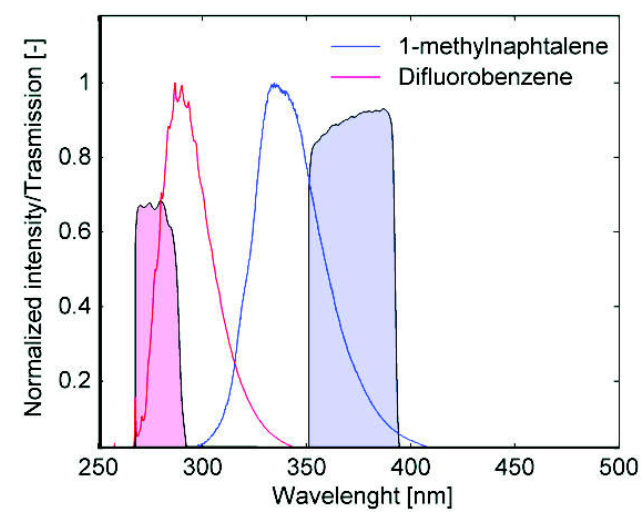

732

Figure 3

733

734

735

736

737

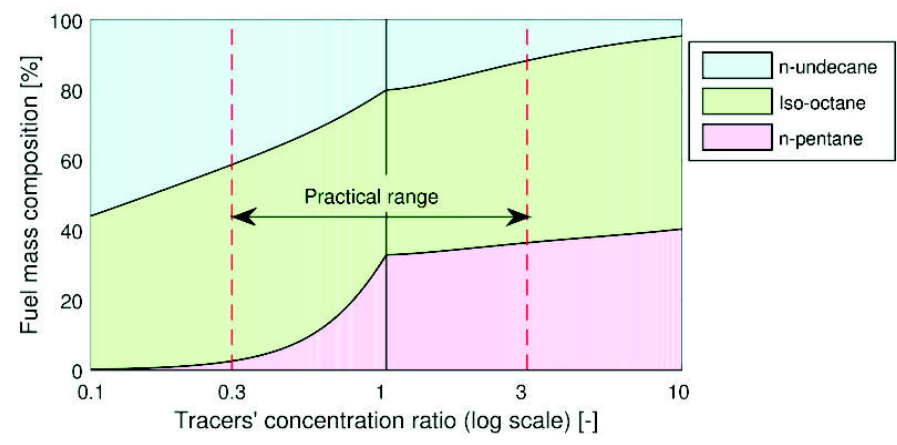

738 Figure 4

739 


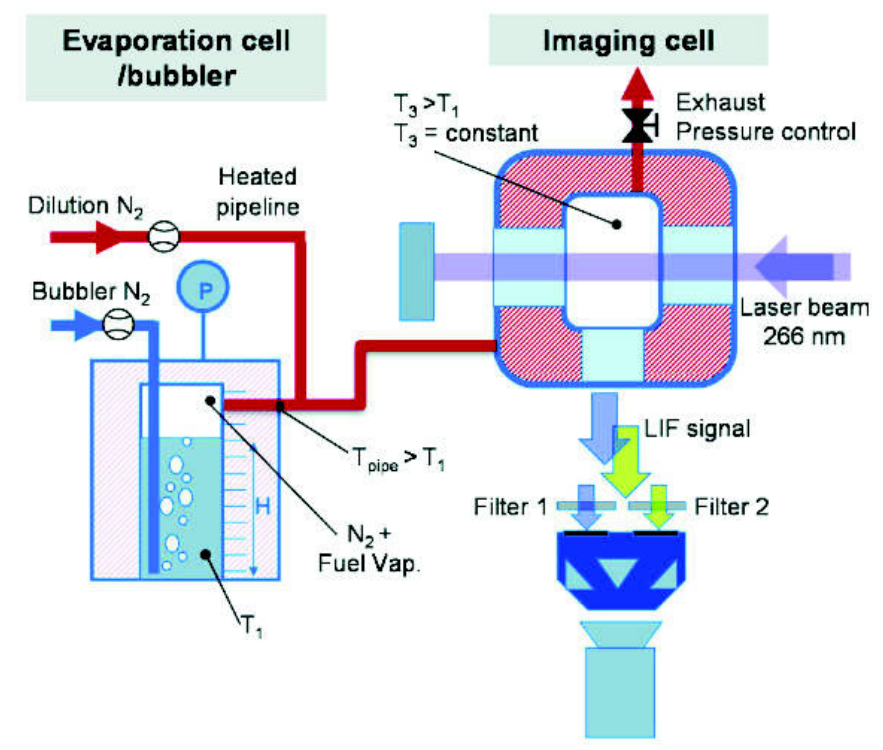

$741 \quad$ Figure 5

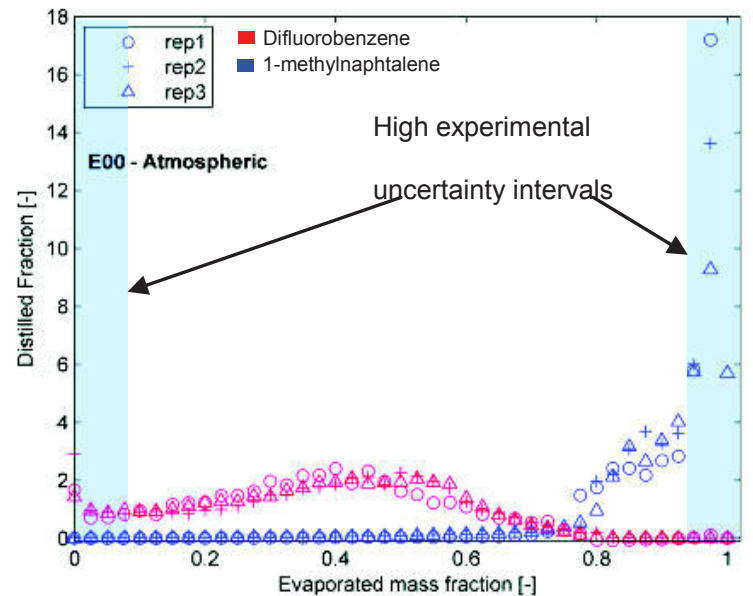

746 Figure 6 


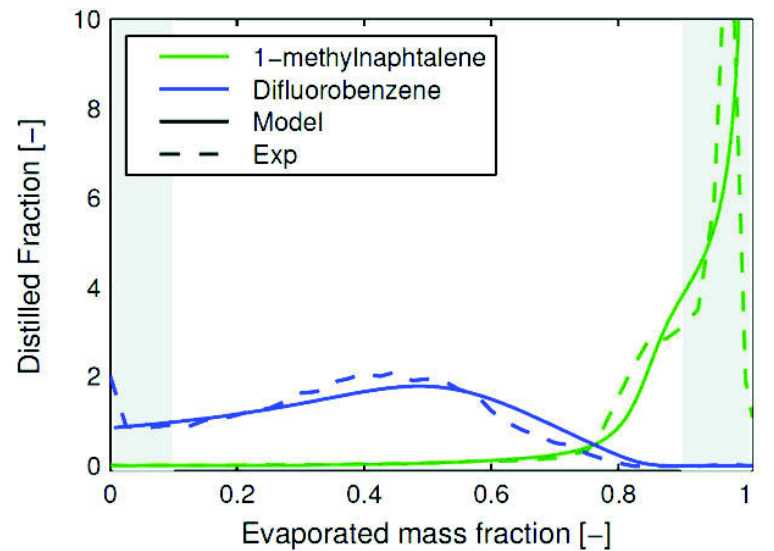

Figure 7

752

753
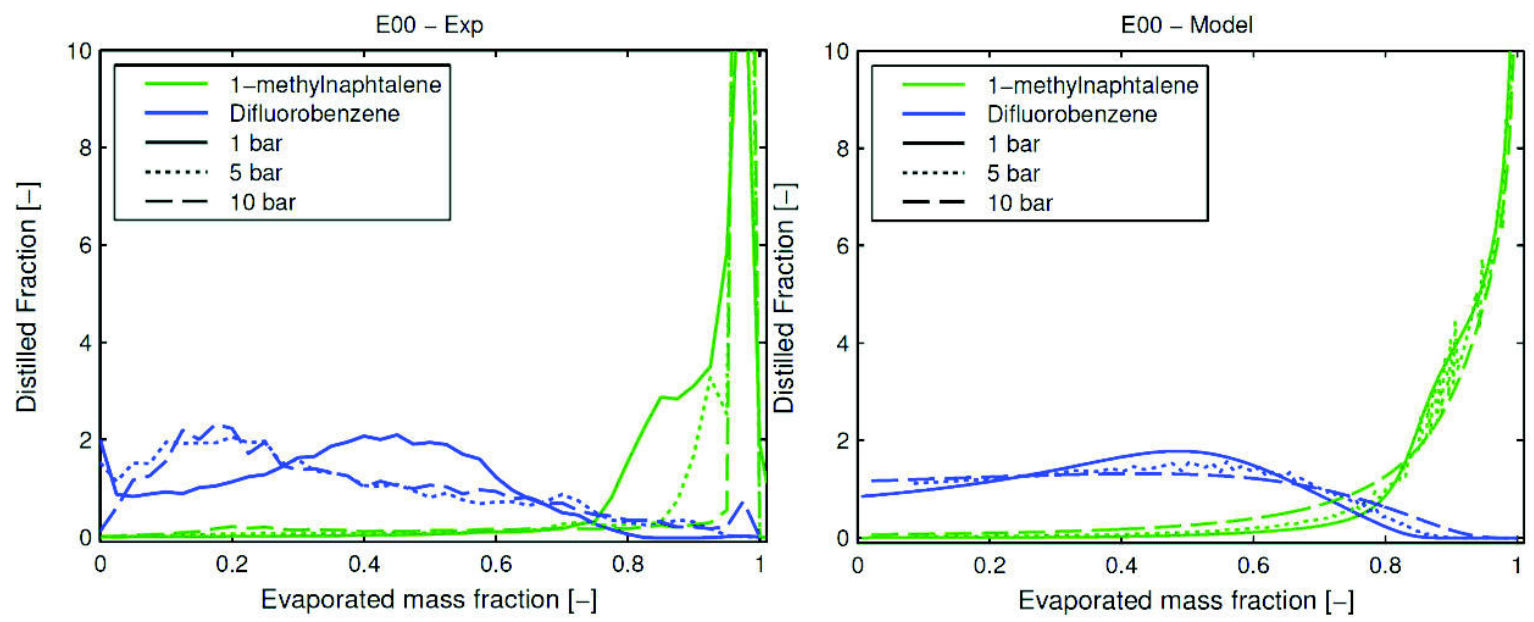

Figure 8

756 

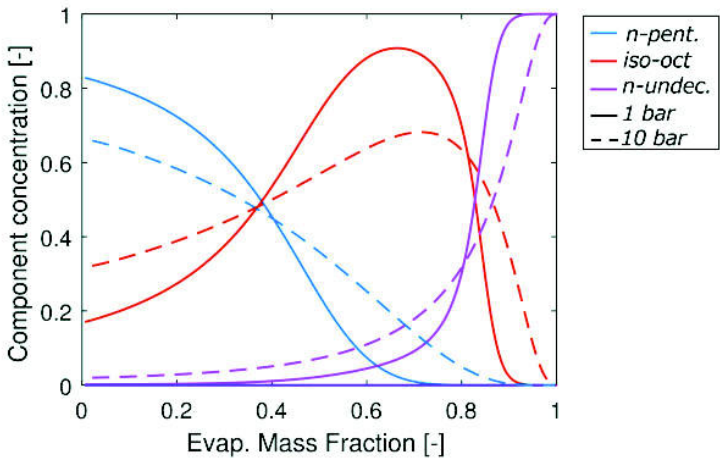

Figure 9
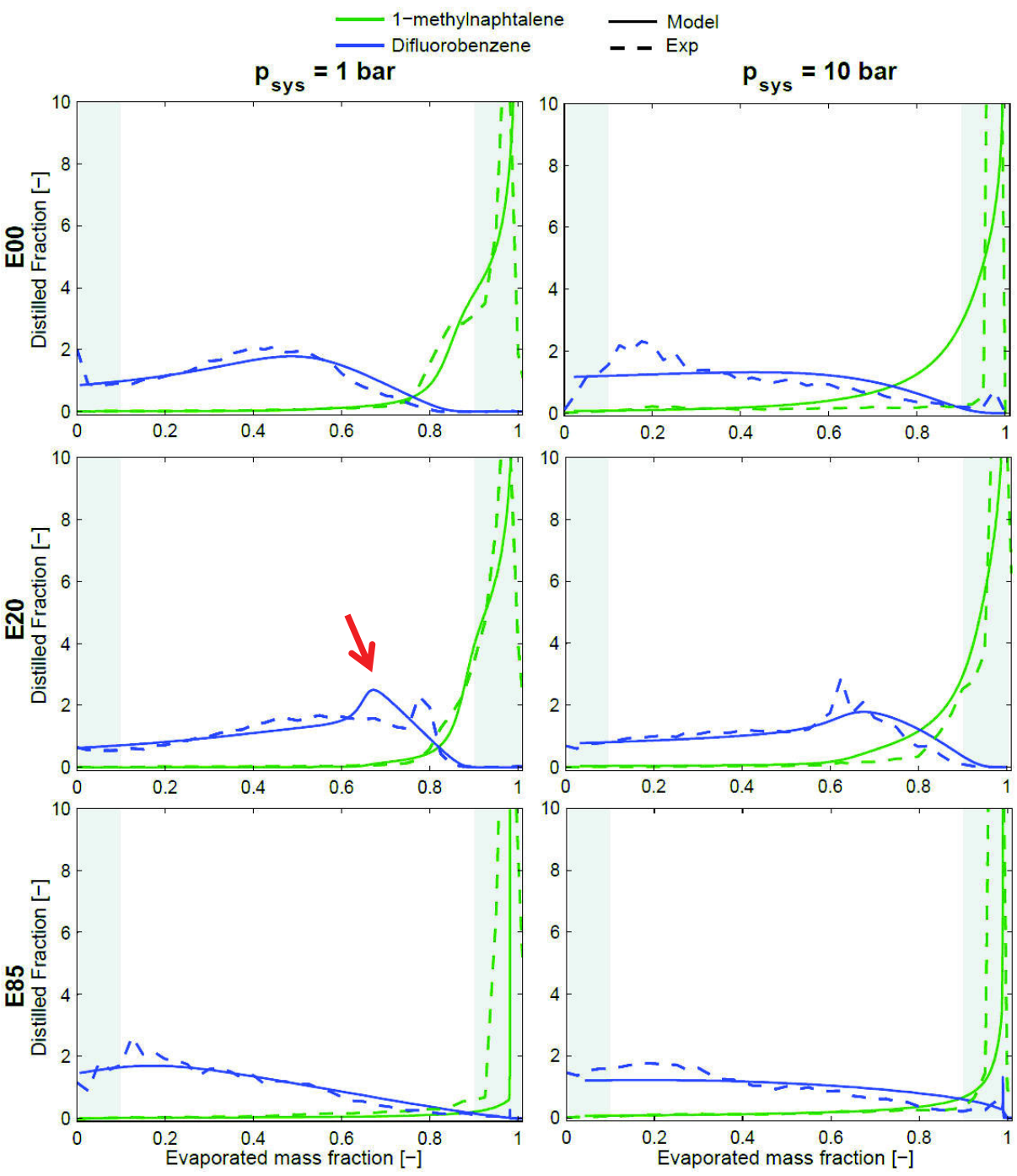

Figure 10 

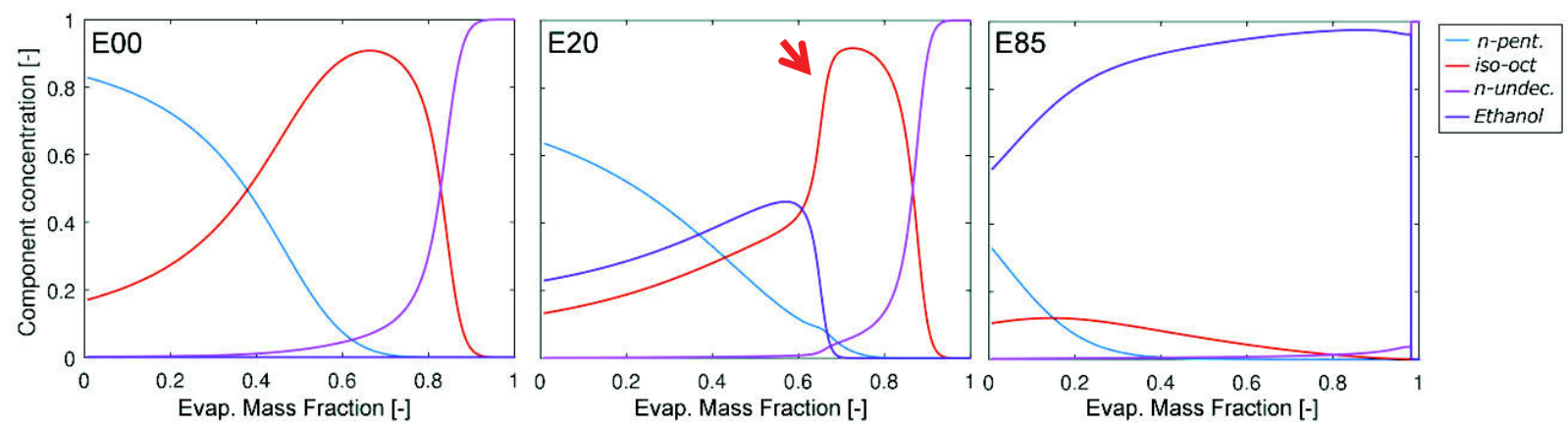

764 Figure 11
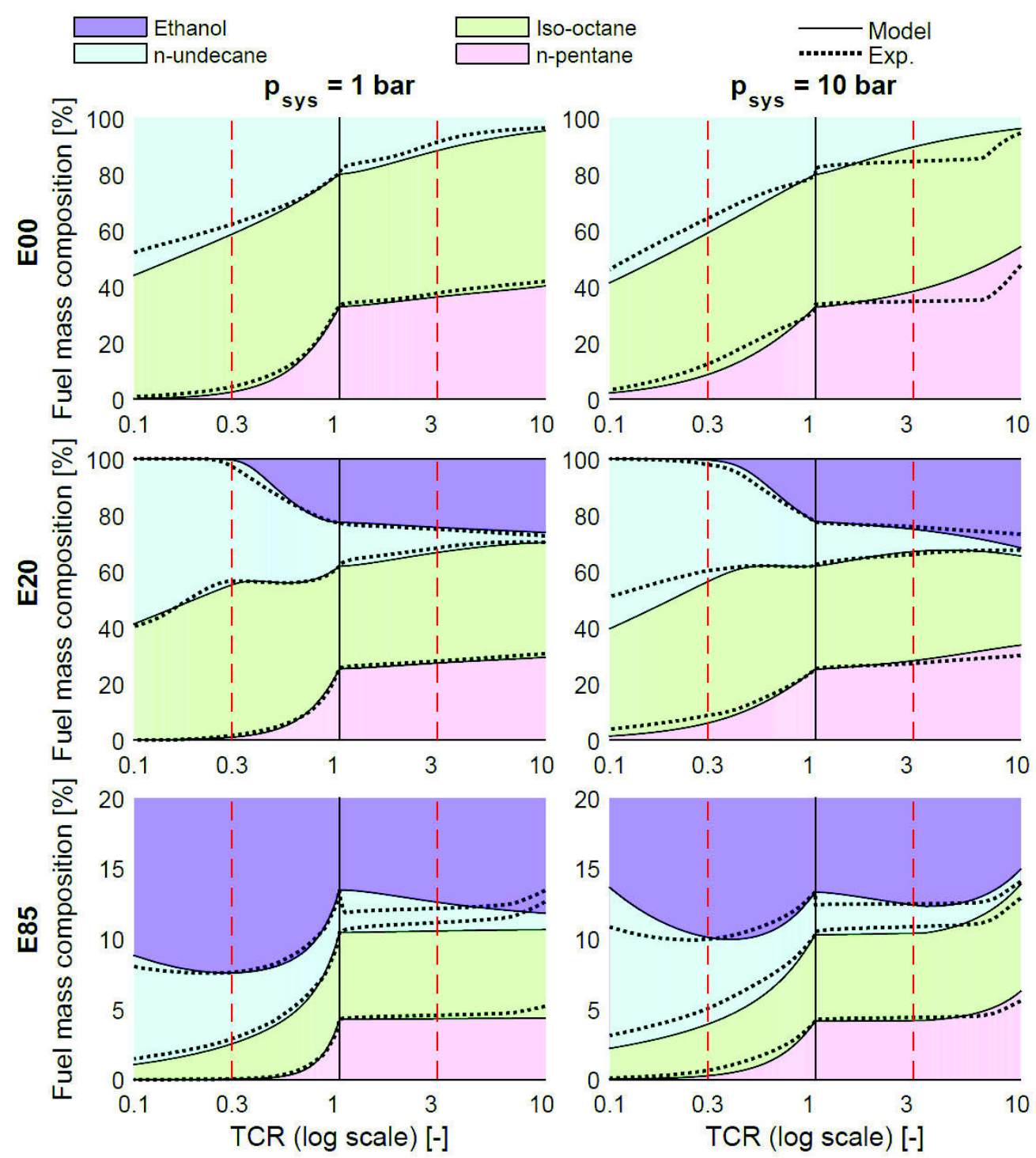


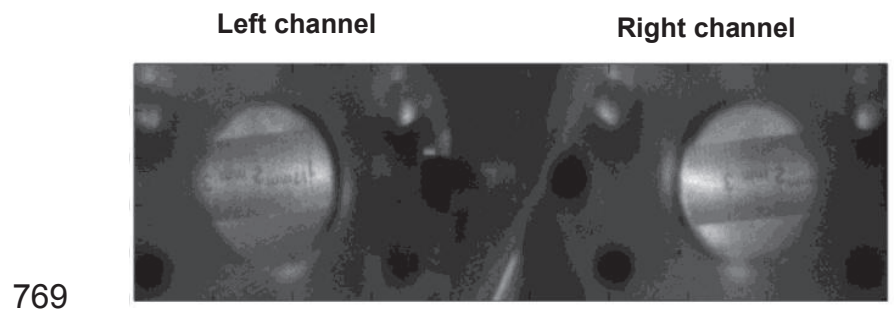

770 Figure 13

771

1-methylnapthalene Difluorobenzene

772

$470 \pm 20 \mathrm{~nm}$

$285 \pm 10 \mathrm{~nm}$

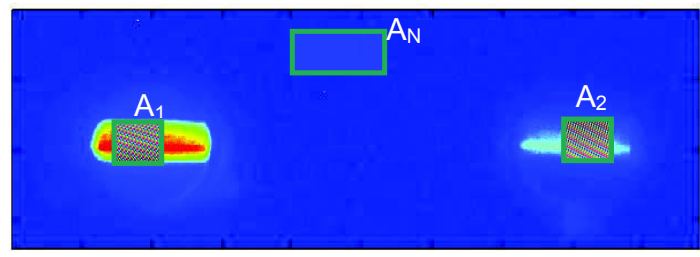

773 Figure 14

\section{4}

